\title{
O Desenvolvimento do Turismo Náutico e a sua Ligação com a Observação do Boto-Cinza (sotalia guianensis) na Região de Cananéia, Litoral Sul do Estado de São Paulo
}

\section{Nautical Tourism Development and its Connection with the Observation of the Estuarine Dolphin (sotalia guianensis) in the Cananéia Region, South Coast of São Paulo State}

\author{
Gislaine de Fátima Filla ${ }^{1}$ \\ Emydio Leite de Araújo Monteiro Filho
}

\section{Resumo}

O boto-cinza é hoje um grande atrativo e gerador de renda para a região estuarina de Cananéia. O crescimento da infra-estrutura turística desta região parece estar intimamente relacionado com o crescimento do interesse em observar estes animais na natureza. Assim, um levantamento das atuais estruturas de alojamento e capacidade náutica da região foi feito nos meses de verão de 2007, através de visitas aos estabelecimentos e entrevistas com pessoas atuantes no turismo náutico. Ficou evidente que as estruturas de alojamento e o uso das embarcações nas três ilhas do estuário variam de acordo com as diferentes categorias de turistas que freqüentam esta região e com o objetivo de suas viagens. Ainda, foi possível notar que a organização em associações e parcerias garantiu um crescimento maior da atividade de observação do boto-cinza, a qual deve ser acompanhada com cuidado para que seja desenvolvida de forma otimizada, conservando os animais e seu habitat natural.

Palavras-chaves: boto-cinza; sotalia guianensis; turismo náutico; Cananéia

\begin{abstract}
The estuarine dolphin (sotalia guianensis) is a big attraction and money maker for the Cananéia estuary region. The increased tourist infrastructure of the region seems to be directly related to the growing interest to observe these animals in loco. Therefore, a survey was done to asses the present boarding and nautical capacity of the region during the summer months of 2007, by means of visits to the establishments and interviews with the people working with nautical tourism. It was evident that the boarding structures and the use of ships on the three islands of the estuary vary according to the different type of tourists that visit the area and their reasons for the trip. Even so, it was possible to note that organized associations and partnerships guaranteed a larger growth and activity of estuarine dolphin observation, which must be carefully followed to ensure proper development and to preserve and maintain the animals in their natural habitat.
\end{abstract}

Keywords: estuarine dolphin; sotalia guianensis; nautical tourism; Cananéia.

\footnotetext{
${ }^{1}$ Doutora em Zoologia; Pesquisadora do Projeto Boto-cinza, Instituto de Pesquisas Cananéia, IPeC. E-mail: gica_filla@yahoo.com.br

${ }_{2}^{2}$ Doutor em Ecologia; Professor Associado do Departamento de Zoologia da Universidade Federal do Paraná, UFPR; Pesquisador do Projeto Boto-cinza, Instituto de Pesquisas Cananéia, IPeC. E-mail: elamf@ufpr.br
} 


\section{Introdução}

No litoral sul do Estado de São Paulo, há uma região de fácil acesso e muito privilegiada para o turismo náutico, ou seja, o turismo que caracteriza-se pela utilização de embarcações com a finalidade da movimentação turística (Ministério do Turismo, 2009). A região estuarina de Cananéia (Fig. 1) apresenta 110 km de extensão, constituída de uma baía (Baía de Trapandé) e três ilhas (Ilha Comprida a leste, Ilha do Cardoso ao sul e Ilha de Cananéia a oeste), com enseadas estreitas nos limites norte (Barra do Icapara) e sul (Barra de Cananéia). Esse sistema estuarino representa um dos mais preservados ecossistemas da costa brasileira, estando legalmente protegido por ser Área de Proteção Ambiental Estadual e Federal (SchaefferNovelli et al., 1990).

Esta região é conhecida como Lagamar e ainda se mantém como o principal reduto da cultura caiçara, que se estende do Estado do Rio de Janeiro até o norte do Estado de Santa Catarina. Merecem destaque o fandango cantado após os mutirões realizados para preparar as terras que serão cultivadas e a varação de canoas, festa realizada após o transporte comunitário das canoas pela mata, até a beira do rio ou beira-mar (Diegues, 2002).

A comunidade caiçara estabelecida em Cananéia é muito antiga, tendo seu início nas primeiras famílias nascidas no regime de 'compadrio', casamento entre branco colonizador e

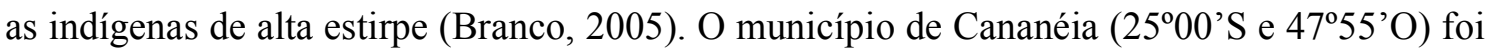
oficialmente fundado em 1531, como importante ponto de controle de navegação no litoral sul paulista e local de construção e reparo de embarcações, possuindo assim as bases para o desenvolvimento de uma incipiente vida comercial (Henrique \& Mendes, 2001). O município é formado por uma parte continental e pela Ilha de Cananéia, ligadas entre si por uma ponte ao norte e por uma travessia com balsa ao sul; e sua população estimada no último levantamento, em 2006, foi de cerca de 14.000 habitantes (IBGE, 2007).

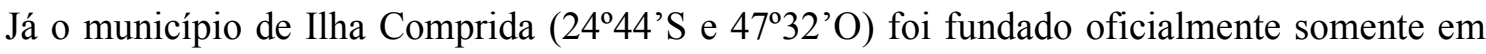
1991, quando a Ilha se emancipou dos municípios de Cananéia e Iguape (Prefeitura Municipal de Ilha Comprida, 2007). Tem uma área territorial de aproximadamente $189 \mathrm{~km}^{2}$, com população fixa de 9.622 habitantes (IBGE, 2007), mas nos meses de verão, a população pode chegar a 938.000 pessoas. A Ilha tem ligação com o Município de Iguape ao norte, através de uma ponte e com a Ilha de Cananéia ao sul, através da travessia de balsa. A sua praia com cerca de $74 \mathrm{~km}$ de extensão é considerada a segunda maior do Brasil (Prefeitura Municipal de Ilha Comprida, 2007). 
Os moradores nativos da Ilha do Cardoso também eram basicamente índios, mestiços e portugueses que vieram no tempo das capitanias hereditárias, para povoar esses lugares estratégicos na beira mar. Exploravam recursos como o ouro e a madeira e cuidavam da terra para que outros invasores não chegassem. Em 1956 o Bairro do Marujá foi fundado, com a construção de 12 casas e dois barracões e em 1962 houve a decretação do Parque Estadual Ilha do Cardoso (PEIC; $25^{\circ} 05^{\prime}$ S e 47 $53^{\prime}$ O) (Rodrigues, 2005). O PEIC é uma Unidade de Conservação de proteção integral, não sendo permitida a extração direta de seus recursos naturais (SNUC, 2000), que abrange uma área aproximada de $151 \mathrm{~km}^{2}$ (Bernardi, 2001).

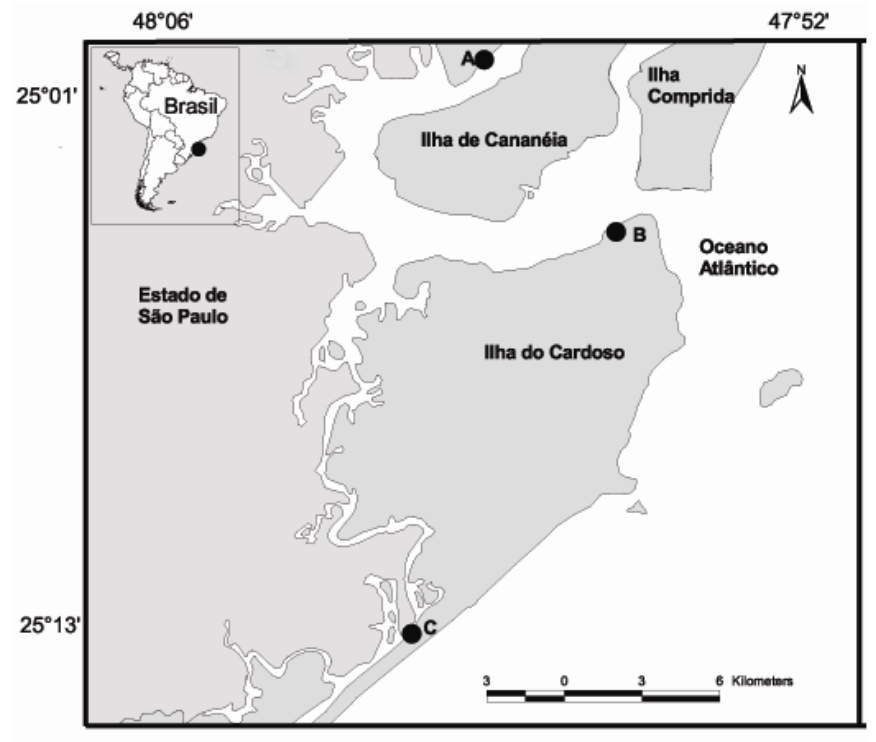

Figura 1 - Região estuarina de Cananéia, litoral sul do Estado de São Paulo, formada pelas três ilhas (Ilha de Cananéia, Ilha Comprida e Ilha do Cardoso).

A letra A corresponde à parte continental do Município de Cananéia; a letra B corresponde à localização do Núcleo Perequê e a letra C à localização da Vila do Marujá, ambas na Ilha do Cardoso.

Fonte: Roberto Fusco Costa, Instituto de Pesquisas Cananéia/IPeC.

Atualmente, a principal atividade econômica da região do Lagamar como um todo é a pesca, sendo praticada pela maior parte da população (Diegues, 2002). Contudo, esta atividade dá lugar ao turismo nos meses de verão, quando passa a ser mais praticado do que a própria pesca em muitas comunidades. No município da Ilha Comprida o turismo aparece como a principal fonte de renda durante o ano todo (SEMA/ SP, 1998). 
Para uma parte dos caiçaras o turismo é negativo, devido ao abandono das atividades de subsistência, que fez com que a vida cotidiana piorasse. Por outro lado, para os caiçaras que criaram atividades econômicas que estão vinculadas à atividade turística, como os proprietários de acampamentos, restaurantes ou mesmo uma parcela de pescadores que vendem o pescado a melhores preços durante a temporada, o turismo é considerado positivo (Rodrigues, 2005).

Há cerca de 40 anos iniciou-se nesta região o turismo náutico, que a princípio era exclusivamente para transportar pescadores esportivos e suas respectivas famílias. Hoje este turismo acontece tanto por conta dos pescadores quanto por pessoas que vêm à região atraídas pelo seu patrimônio natural, histórico e cultural. Por conta disso, a infra-estrutura das comunidades se desenvolveu muito voltada para receber o turista. Muitas pousadas, hotéis, campings, marinas e garagens náuticas se instalaram na região de Cananéia (ilha e continente), no sul da Ilha Comprida e Ilha do Cardoso.

Um grande destaque atrativo desta região é o boto-cinza (Sotalia guianensis) que promove a alegria de centenas de turistas/ ano. O boto-cinza utiliza águas tropicais, costeiras e estuarinas (Carvalho, 1963) e é encontrado desde Honduras $\left(15^{\circ} 58^{\prime} \mathrm{N}, 85^{\circ} 42^{\prime} \mathrm{W}\right.$; da Silva \& Best, 1996) até o Estado de Santa Catarina, no sul do Brasil (27³5S, 48³4'W; Simões-Lopes, 1988), sendo amplamente distribuído pela costa brasileira. Trata-se de um cetáceo de pequeno porte, com comprimento máximo de 2,06m (Barros, 1991) e peso máximo observado de $121 \mathrm{~kg}$ (Rosas, 2000). Sua dieta inclui principalmente peixes, crustáceos e cefalópodes (Leatherwood \& Reeves, 1983; Oliveira, 2003; Daura-Jorge, 2007) e com indícios de seletividade de presas entre sexos e entre diferentes fases de desenvolvimento (Oliveira, 2003; Oliveira et al., 2008).

São animais que vivem em agrupamentos, podendo alguns indivíduos ser observados sozinhos, sobretudo em áreas protegidas, como interior de baías e estuários (Monteiro-Filho, 2000; Filla, 2004; Filla \& Monteiro-Filho, no prelo) e estão presentes na região de Cananéia o ano todo (ver Filla, 2008), podendo ser facilmente observado tanto a bordo de embarcações quanto a partir de alguns pontos em terra nas três ilhas do Lagamar. Assim, considerando todas as características desta região, o presente estudo foi desenvolvido visando a conhecer as atuais estruturas de alojamento e capacidade náutica da região e a sua possível ligação com o desenvolvimento do turismo de observação deste cetáceo. 


\section{Método}

A pesquisa foi realizada nos meses de verão de 2007, nas três ilhas da região e na parte continental do município de Cananéia. Dividiu-se em levantamentos de dados quantitativos (alojamentos e garagens náuticas) e registro de depoimentos de 'pessoas chaves' que atuam no turismo de observação dos botos-cinza nesta região.

\subsection{Levantamento das estruturas de turismo na região}

Uma visita foi feita em cada uma das garagens náuticas comerciais, que se localizam nos municípios de Cananéia (Ilha e continente, no bairro Porto Cubatão) e de Ilha Comprida (no Boqueirão Sul, limite sul), para levantamento de embarcações em atividade turística. Do mesmo modo, um levantamento das potenciais vagas da rede hoteleira da região foi realizado, através de visitas aos locais ou por contato telefônico.

Os dados aqui registrados foram levantados com a ajuda e depoimentos de moradores da região, nos meses de verão de 2007 e organizados na forma de tabelas. A pesquisa foi muito facilitada pelo fato de há muito anos o Instituto de Pesquisas Cananéia (IPeC) atuar com pesquisa científica, educação e cultura na região e portanto, já estar inserido na comunidade, sendo aceito por diversos órgãos governamentais locais, como Parque Estadual Ilha do Cardoso, Instituto de Pesca - Núcleo do Litoral Sul (SP) e IBAMA; por associações não governamentais, como Associação dos Monitores Ambientais de Cananéia - AMOANCA, Associação Náutica de Cananéia; além dos próprios moradores das comunidades das três ilhas que muito contribuíram para levantamento dos dados aqui apresentados. Segundo Martins (1993, apud Nunes, 2003) teorias que se apóiam no distanciamento do sujeito do seu objeto de pesquisa foram contrariadas, mas como afirmado pelo mesmo autor, o pesquisador deve deixar de ser um mero observador para ser parte no processo de pesquisa. Desta forma, por sermos integrantes da equipe do instituto, pudemos alcançar resultados mais precisos tanto no número e tipo de estruturas de turismo quanto na veracidade dos depoimentos dos entrevistados.

Vale ressaltar que os dados de alojamento dizem respeito somente aos estabelecimentos comerciais, pois casas particulares são alugadas (por taxa diária) para turistas nos meses de verão e também muitas pessoas ficam alojadas em casas de parentes ou amigos. Da mesma forma, somente garagens náuticas comerciais foram levantadas, uma vez que muitas residências contam com garagens náuticas particulares e muitas embarcações são vistas 
ancoradas junto às bóias, sendo estas principalmente de moradores locais. Por questão de sigilo de informação estes estabelecimentos comerciais não foram identificados.

\subsection{Entrevistas}

A modalidade de entrevista adotada foi a "parcialmente estruturada", apresentando alguns tópicos fixos e outros que são definidos conforme o andamento da entrevista, visando a canalizar o diálogo para as questões a serem investigadas (Haguette, 1992; Richardson et al., 1999; Vietler, 2002; Albuquerque \& Lucena, 2004). Desta forma, as entrevistas foram realizadas informalmente, como 'bate papo', constituídas de quatro questões abertas, em que o entrevistado ia contando suas histórias e experiências livremente, sendo estimulado em alguns pontos mais relevantes:

Pergunta 1: Como você começou na atividade de turismo com embarcação?

Pergunta 2: Como você trabalha hoje? O que mudou?

Pergunta 3: Acha que os botos sofrem alguma interferência por parte das embarcações?

Pergunta 4: Está satisfeito com seu trabalho? Pretende continuar? Quais são seus planos pro futuro?

As respostas foram sendo anotadas simultaneamente às entrevistas, com autorização prévia dos entrevistados e transcritas na primeira pessoa, relatando fielmente os depoimentos. Três proprietários de embarcações que atuam no turismo de observação do boto-cinza em Cananéia foram entrevistados. Dois deles são proprietários das duas empresas que atualmente trabalham com passeios de escunas (embarcações grandes de madeira com motor de centro) na região e o terceiro entrevistado trabalha com voadeira (barco de alumínio com motor de popa). O anonimato dos entrevistados foi mantido e os autores são muito agradecidos pela atenção dispensada pelos três entrevistados.

\section{Desenvolvimento do Tema}

\subsection{Principais resultados e discussão}

As diferenças entre os tipos de estruturas encontradas nas comunidades visitadas, organizadas na forma de tabelas (Tabelas de 1 a 6) deixam claro que se destinam a diferentes categorias de turistas que freqüentam esta região. 
Em relação aos alojamentos, foi possível categorizar os turistas em 1) aqueles que se hospedam nas pousadas, hotéis e clubes náuticos locais, utilizam também os restaurantes e lanchonetes e, acabam contribuindo mais com o comércio local; 2) os jovens que acampam na região, não preocupados com conforto, mas sim com a economia e diversão; e 3) aqueles que têm casa na região, ou se hospedam na casa de parentes e amigos.

Com relação ao uso de embarcações, os turistas puderam ainda ser separados em pescadores esportivos que utilizam as marinas, que vêm exclusivamente para a pesca e eventualmente trazem a família. utilizam embarcações das marinas ou guardam suas embarcações de alumínio nas mesmas; 2) os ecoturistas que vêm atraídos pela natureza, história e culturas locais, realizam passeios de escunas ou voadeiras das comunidades; 3) os que têm embarcações próprias, geralmente grandes lanchas, iates e jet skis com motores potentes e as guardam em garagens náuticas particulares, anexas às grandes casas de veraneio; e 4) os turistas que vêm para a região para aproveitar as praias, vêm em grupo familiar ou de amigos e passam a temporada à beira mar, muitas vezes não fazendo uso de nenhum tipo de embarcação, exceto pela balsa que liga as Ilhas de Cananéia e Comprida.

\subsection{Ilha de Cananéia}

Duas marinas estão em atividade na Ilha de Cananéia, sendo uma próxima ao centro da cidade e outra anexa a um hotel a $6 \mathrm{~km}$ do portal de entrada da cidade. Os turistas que procuram estes estabelecimentos vêm à região para pescar e também a passeio. Os dados das marinas e da rede hoteleira de Cananéia se encontram nas tabelas 1 e 2, respectivamente.

Tabela 1 - Características das marinas da Ilha de Cananéia, SP.

\begin{tabular}{|l|c|c|c|c|c|}
\hline & $\begin{array}{c}\text { Número de } \\
\text { funcionários }\end{array}$ & $\begin{array}{c}\text { Número de } \\
\text { barqueiros }\end{array}$ & $\begin{array}{c}\text { Embarcaçóes } \\
\text { próprias }\end{array}$ & Motores & $\begin{array}{c}\text { Capacidade da } \\
\text { garagem } \\
\text { náutica }\end{array}$ \\
\hline Marina I & 13 & 00 & 15 & $\begin{array}{c}1 \text { centro e } \\
14 \text { popa }\end{array}$ & $\begin{array}{c}45 \text { embarcações } \\
\text { com motor de } \\
\text { popa }\end{array}$ \\
\hline Marina II & 07 & 00 & 00 & 00 & $\begin{array}{c}70 \text { embarcações } \\
\text { com motor de } \\
\text { centro e popa }\end{array}$ \\
\hline Total & 20 & 00 & 15 & & 115 \\
\hline
\end{tabular}

Fonte: Elaborada pelos autores. 
Tabela 2 - Características dos alojamentos da Ilha de Cananéia, SP.

\begin{tabular}{|l|c|c|c|}
\hline $\begin{array}{c}\text { Tipo de } \\
\text { alojamento }\end{array}$ & $\begin{array}{c}\text { Quantidade de } \\
\text { estabelecimentos }\end{array}$ & $\begin{array}{c}\text { Número de } \\
\text { quartos }\end{array}$ & $\begin{array}{c}\text { Número potencial de } \\
\text { hóspedes }\end{array}$ \\
\hline Pousada & 20 & 172 & 650 \\
\hline Hotel & 08 & 178 & 652 \\
\hline Clube náutico & 01 & 16 & 111 \\
\hline Camping & 01 & 50 barracas & 1.513 \\
\hline Total & 30 & 366 quartos & \\
\hline
\end{tabular}

Fonte: Elaborada pelos autores.

É possível verificar pelos dados das tabelas, que esta ilha já conta com uma boa estrutura de turismo, no que se refere ao número de pousadas e hotéis, que é bem maior do que nas demais (Tabelas 3, 5 e 6), porém tem disponível somente uma área de camping. Possui uma garagem náutica e um clube náutico, além do Trapiche Municipal com escunas e lanchas diariamente à disposição para passeios e/ ou pescarias. Esta ilha recebe a maior parte dos turistas dos ecoturistas, que procuram a região atraídos pelo sossego, tranqüilidade, belezas naturais, conteúdo histórico e cultural. É no Trapiche Municipal que embarcam rumo à "Baía dos Golfinhos", nome popular da Baía de Trapandé, muito utilizado pelos condutores das embarcações que realizam turismo de observação do boto-cinza. Nas outras localidades visitadas, este tipo de turismo é praticamente ausente.

\subsection{Cananéia continental}

Seis marinas estão em atividade atualmente no Bairro Porto Cubatão, na parte continental de Cananéia. Todas as marinas são anexas às únicas pousadas do local, neste trabalho chamados de Hotel/ Marina, que totalizam 6 estabelecimentos, com 63 quartos e um potencial de receber 233 hóspedes. Os turistas que procuram estes estabelecimentos são exclusivamente pescadores esportivos, alguns acompanhados dos familiares que vêm a passeio. Os dados das marinas Cananéia continental se encontra na Tabela 3. 
Tabela 3 - Características das marinas do Bairro Porto Cubatão, Cananéia continental, SP.

\begin{tabular}{|l|c|c|c|c|c|}
\hline & $\begin{array}{c}\text { Número de } \\
\text { funcionários }\end{array}$ & $\begin{array}{c}\text { Número de } \\
\text { barqueiros }\end{array}$ & $\begin{array}{c}\text { Embarcações } \\
\text { próprias }\end{array}$ & Motores & $\begin{array}{c}\text { Capacidade da } \\
\text { garagem náutica }\end{array}$ \\
\hline Marina I & 09 & 07 & 12 & Popa & $\begin{array}{c}40 \text { embarcações } \\
\text { com motor de } \\
\text { popa }\end{array}$ \\
\hline Marina II & 02 & 01 & 02 & Popa & $\begin{array}{c}\text { 04 embarcações } \\
\text { com motor de } \\
\text { popa }\end{array}$ \\
\hline Marina III & 07 & 00 & 13 & 2 centro e & $\begin{array}{c}200 \text { embarcações } \\
\text { com motor de } \\
\text { popa }\end{array}$ \\
\hline Marina IV & 00 & 01 & 04 & Popa & $\begin{array}{c}20 \text { embarcações } \\
\text { com motor de } \\
\text { popa }\end{array}$ \\
\hline Marina V & 02 & 00 & 04 & Popa & $\begin{array}{c}\text { p9 embarcações } \\
\text { com motor de } \\
\text { popa }\end{array}$ \\
\hline Marina VI & 08 & 00 & 08 & Popa & $\begin{array}{c}80 \text { embarcações } \\
\text { com motor de } \\
\text { popa }\end{array}$ \\
\hline
\end{tabular}

Fonte: Elaborada pelos autores.

$\mathrm{Na}$ parte continental do município, nota-se que o número de garagens náuticas é muito grande, sendo o maior da região (Tab. 3) e todas as opções de alojamento estão anexas a elas e vice-versa. Nesta área os turistas são quase em sua totalidade pescadores esportivos e não há qualquer tipo de estrutura turística para receber outras categorias de turistas.

\subsection{Ilha Comprida}

Duas marinas estão em atividade atualmente no Bairro Boqueirão Sul, no município de Ilha Comprida, no limite sul desta ilha. Na face oeste da ilha estão as duas marinas, uma fazendo parte de um Clube Náutico e outra anexa a uma pousada. Os turistas que procuram estes estabelecimentos são quase que exclusivamente pescadores esportivos. Os dados das marinas 
e da rede hoteleira da ponta sul da Ilha Comprida se encontram nas tabelas 4 e 5, respectivamente.

Tabela 4 - Características das marinas do Boqueirão Sul, limite sul da Ilha Comprida, SP.

\begin{tabular}{|l|c|c|c|c|c|}
\hline & $\begin{array}{c}\text { Número de } \\
\text { funcionários }\end{array}$ & $\begin{array}{c}\text { Número de } \\
\text { barqueiros }\end{array}$ & $\begin{array}{c}\text { Embarcações } \\
\text { próprias }\end{array}$ & Motores & $\begin{array}{c}\text { Capacidade da } \\
\text { garagem náutica }\end{array}$ \\
\hline Marina I & 15 & 02 & 06 & Popa & 00 \\
\hline Marina II & 01 & 00 & 00 & 00 & $\begin{array}{c}60 \text { embarcações } \\
\text { com motor de } \\
\text { popa }\end{array}$ \\
\hline Total & 16 & 02 & 06 & & 60 \\
\hline
\end{tabular}

Fonte: Elaborada pelos autores.

Tabela 5 - Características dos alojamentos do Boqueirão Sul, limite sul da Ilha Comprida, SP.

\begin{tabular}{|l|c|c|c|}
\hline \multicolumn{1}{|c|}{$\begin{array}{c}\text { Tipo de } \\
\text { Alojamento }\end{array}$} & $\begin{array}{c}\text { Quantidade de } \\
\text { estabelecimentos }\end{array}$ & $\begin{array}{c}\text { Número de } \\
\text { quartos }\end{array}$ & $\begin{array}{c}\text { Número potencial de } \\
\text { hóspedes }\end{array}$ \\
\hline Pousada & 04 & 54 & 172 \\
\hline Hotel & 01 & 16 & 64 \\
\hline Hotel/ Marina & 01 & 35 & 24 \\
\hline Clube Náutico & 01 & 06 & 1740 \\
\hline Camping & 05 & 105 quartos & 2170 \\
\hline Total & 12 & E 580 barracas & \\
\hline
\end{tabular}

Fonte: Elaborada pelos autores.

Nesta ponta da Ilha Comprida, encontram-se poucos estabelecimentos, talvez pela sua grande proximidade à Ilha de Cananéia. Contudo, é possível distinguir dois tipos de estruturas, montadas para diferentes categorias de turistas: 1) aquelas que ficam voltados para o canal interno (face oeste) são direcionadas para os pescadores esportivos, como as duas marinas e 
seus alojamentos anexos (Tabs. 4 e 5); e 2) as que ficam próximos ao mar, na face leste da ilha, são voltadas para o turista praiano, ou seja, aquele que quer somente aproveitar o verão tomando banho de sol e de mar; comendo porções com cervejas e refrigerantes. Neste local encontram-se os campings, as poucas pousadas, o único hotel (Tab. 5) e barzinhos à beira mar.

\subsection{Ilha do Cardoso}

O Parque Estadual Ilha do Cardoso possui instalações que permitem a hospedagem de turistas em dois diferentes locais (Tab. 6). Por ser uma área de uso controlado, a ilha não possui nenhuma garagem náutica comercial.

Tabela 6 - Características dos alojamentos do Núcleo Perequê e da Vila do Marujá, ambos na Ilha do Cardoso, SP.

\begin{tabular}{|l|c|c|c|}
\hline \multicolumn{1}{|c|}{ Tipo de } & \multicolumn{1}{|c|}{$\begin{array}{c}\text { Quantidade de } \\
\text { estabelecimentos }\end{array}$} & $\begin{array}{c}\text { Número de } \\
\text { Quartos }\end{array}$ & $\begin{array}{c}\text { Número } \\
\text { potencial de } \\
\text { hóspedes }\end{array}$ \\
\hline $\begin{array}{l}\text { Áreas de camping no } \\
\text { Núcleo Perequê }\end{array}$ & 06 quintais & 36 barracas & 144 \\
\hline $\begin{array}{l}\text { Quartos nas casas de } \\
\text { moradores do Núcleo } \\
\text { Perequê }\end{array}$ & 02 & 03 & 10 \\
\hline $\begin{array}{l}\text { Alojamentos do Parque } \\
\text { Estadual Ilha do Cardoso }- \\
\text { Núcleo Perequê }\end{array}$ & 01 & 12 & 72 \\
\hline $\begin{array}{l}\text { Áreas de camping na Vila } \\
\text { do Marujá }\end{array}$ & 44 & 270 barracas & 640 \\
\hline $\begin{array}{l}\text { Quartos nas casas de } \\
\text { moradores na Vila do } \\
\text { Marujá }\end{array}$ & 05 & 13 & 51 \\
\hline Pousadas da Vila do Marujá & --- & 306 barracas & \\
\hline \begin{tabular}{l} 
Total \\
\hline
\end{tabular} & 15 & 80 & 358 \\
\hline
\end{tabular}

Fonte: Elaborada pelos autores. 
É possível notar diferenças entre as duas áreas procuradas pelos turistas na Ilha do Cardoso (Tab. 6): no norte da ilha, onde encontra-se as instalações do Núcleo Perequê, há a Praia do Itacuruçá, que fica voltada para a "Baía dos Golfinhos" e é ponto de desembarque de todos os turistas que vêm à região para observar o boto-cinza, seja a bordo de escunas, de barcos pequenos com motor de popa ou mesmo pequenas embarcações de pescadores locais. Dois restaurantes à beira-mar permitem que o turista ali passe o dia. Poucas pessoas se hospedam neste ponto da ilha, porque as únicas instalações permitidas são seis áreas de camping (próprios quintais dos moradores locais) e o alojamento do parque. Este último não é aberto ao público em geral, sendo restrito a grupos de estudo, principalmente escolas e pesquisadores.

Na Vila do Marujá, na ponta sul da Ilha do Cardoso há pousadas; residências adaptadas para melhor receber o turista, com mais um quarto e banheiro; e principalmente áreas de camping nos quintais. Isto porque a maior parte dos turistas ali recebidos são os campistas, geralmente jovens que buscam as praias, as belezas naturais e os barzinhos desta vila. O número de turistas é limitado e controlado, chegando ao seu limite em feriados nacionais, como viradas de ano e o carnaval, mas como o acesso a ela é difícil, já ocorre uma triagem natural dos turistas. Segundo Rodrigues (2005), um morador local e líder comunitário, Seu Ezequiel, descreve cinco categorias de turistas, pelo ponto de vista dos próprios moradores: 1) "turistasveranistas" - aqueles que têm casa na região e que, pelo prisma da comunidade local, não trazem quase nenhum benefício socioeconômico; 2) os "pescadores-amadores" - vistos como agressivos porque matam muitos filhotes de peixes; 3) o "grupo que vem de iate" que deixam recursos somente para as comunidades de Cananéia e Ilha Comprida e ainda provocam erosão com as marolas grandes que provocam; 4) os "campistas", geralmente de baixa renda, o maior grupo de turistas do bairro e que hoje com consciência de conservação e destino correto do lixo; e 5) o "grupo que aluga alojamentos", que é o grupo que deixa mais recursos financeiros. Durante o período de estudo, a aplicação do questionário foi direcionado a três diferentes moradores da região. As três pessoas escolhidas para serem entrevistadas neste estudo estão ligadas às atividades turísticas na região desde o seu começo e optaram por ocupar o nicho totalmente vago do turismo náutico, como segue:

Entrevistado 1: "Nasci e fui criado na Vila do Marujá, na minha infância eu convivi com um 'avô de coração', um filósofo italiano que teve muita influência na minha visão de valor da natureza. Em 1965, quando a ilha nem era parque ainda, eu trabalhava numa serraria, mas ficava incomodado em saber que estava mexendo com árvores derrubadas, então resolvi sair 
e fui trabalhar com pesca com meu pai. Em 1968/70 levava pessoas, de vez em quando, com bateira*, eram pescadores esportivos e alguns traziam junto suas famílias pra passear. Nestes passeios, em que eu levava mulheres e crianças pra verem as belezas da região incluindo o boto, eu ficava sonhando em um dia ter um barco bem grande e trabalhar só com turistas e as belezas da natureza. Quando vim morar na Ilha de Cananéia aluguel os quartos de minha antiga casa para amigos. Então o potencial para turismo me chamou a atenção e propus para os moradores locais que começássemos a pensar em efetivar esta atividade na vila. No começo o povo queria me bater, diziam que o turismo iria acabar com a ilha. Hoje, é a segunda atividade econômica local, só perdendo pra pesca e eu tenho lá uma pousada, exatamente na casa onde passei a minha infância. Somente em 1998 pude inaugurar minha primeira escuna para passeios. Todos foram contra e me achavam louco, o primeiro ano realmente foi fraco, o segundo foi bom e o terceiro começou a dar certo. Mas é assim mesmo, nós também nascemos pequenos, senão já nasceríamos adultos. Bem nesta época, o IPeC começou seus cursos de Biologia do Boto-cinza e começamos a trabalhar juntos. Hoje somos parceiros em diversos cursos, atividades com crianças, comunidades locais, eventos, e esta parceria faz toda a diferença, só tem a somar (...). A parceria 'Empresa Boto-cinza' com os outros proprietários de escuna é mantida até hoje. Nós criamos um rodizio entre as escunas e montamos um caixa único, dividimos os clientes e o faturamento, mas respeitamos quando os grupos pedem pra realizar o passeio com determinada escuna, as outras abrem mão de sua vez no rodízio. Pra entrar neste esquema, tem que participar do 'Programa Cananéia tem Parque', levando gratuitamente, por um ano, as crianças da região para terem aula no Parque Estadual Ilha do Cardoso. Eu e meu sócio na empresa sempre fizemos isso, os outros não querem fazer, querem lucro imediato. Além disso, os cursos do IPeC cresceram junto com minha empresa e trabalhamos em conjunto também. Eu acho que aumentou muito a quantidade de botos de 1970 pra cá. O potencial turístico da região restringe-se aos meses de verão, então acredito que não prejudica aqui porque nos outros nove meses do ano, dá tempo do que foi prejudicado se recuperar. Comparado a grandes pólos turísticos que trabalham com passeios de escuna, como Balneário Camburiú e Florianópolis (ambos em Santa Catarina), proporcionalmente Cananéia está até melhor. Estou satisfeito com minhas quatro embarcações que hoje fazem os passeios pela região. As tripulações também são ótimas, sempre digo pros mestres e barqueiros que não adiantam grandes barcos sem grandes tripulações e vice-versa. Agora estou contratando também barqueiros um pouco mais velhos, sinto que os meninos podem não passar segurança (apesar de serem ótimos!) a todos os públicos, então diversifiquei. Hoje 80 a 90\% dos meus clientes fazem contato prévio pela 
Internet ou telefone, então vou montar um escritório interno no CEAGESP e ter um quiosque na beira mar para atender aos turistas pessoalmente."

*embarcação pequena de madeira, sem casaria e com motor de centro, típica de pequenos de pescadores da região.

Entrevistado 2: "Eu morava na Ilha de Cananéia e em 1974 comprei uma bateira em sociedade com meu pai para transportar mercadorias para as comunidades mais distantes. De vez em quando levava uma ou duas pessoas para pescar, sendo que neste barco cabiam oito pessoas. Em 1976 consegui comprar uma bateira um pouco maior, que cabiam 12 pessoas para levá-las para pescar, vendo que este mercado poderia crescer. Nesta época, o Aquário de São Vicente capturava os botos num canal atrás da Ilha da Casca e eu ajudava nesta atividade. Então o boto morria lá no aquário e eles vinham aqui pegar outro e mais outro... Em 1978 comecei a trabalhar no Parque Estadual Ilha do Cardoso e durante 16 anos fui mestre da balsa 'Marujá' que transportava 60 pessoas e 04 carros. Em 1982/3 iniciou o 'Projeto Tartaric' no parque, que precisava transportar muitas pessoas até a Ilha do Cardoso e então comprei dois barcos que juntos carregavam quase uma excursão que cabia num ônibus. Mais ou menos em 1997 começou o 'Projeto Cananéia tem Parque', em que as escunas levavam as crianças da região gratuitamente para o Parque Estadual Ilha do Cardoso e em troca recebiam indicações para agências de turismo de São Paulo. Nesta época começou o interesse de turistas para ver o boto e então eu e dois outros proprietários de escunas fundamos juntos a empresa 'Boto-cinza' que é mantida até hoje, para turismo de observação de botos na natureza. Em 2004 consegui finalmente comprar sozinho uma escuna com capacidade para 99 passageiros e dois tripulantes, tendo vendido duas lanchas, minha caminhonete e um barco para fazer este negócio. Há dez ou quinze anos atrás, ninguém vinha pra Cananéia pra ver botos, neste ano de 2007, só no carnaval foram 700 pessoas em dois dias de escuna exclusivamente para isso. Levei ainda 193 pessoas pra Vila do Marujá e mais 20 viagens de lancha neste mesmo feriado. O turismo para ver boto cresceu muito e hoje vivo deste ramo. Acho que os barcos não prejudicam os botos não, pois no canal mais interno não tinha boto e agora tem... Não foi fácil chegar até aqui, comecei do nada, não sabia nem ligar o motor... mas hoje estou muito satisfeito com meu trabalho. Pretendo não parar por aqui, quero vender uma de minhas escunas e comprar outra com capacidade bem maior. Aí sim, ficarei mais feliz!" 
Entrevistado 3: "Comecei bem moleque, trabalhando com meu pai, levando pessoas para a Vila do Marujá há cerca de 20 anos atrás. Depois que aprendi a pilotar, pilotava voadeiras particulares. Com o tempo e muita economia, consegui comprar duas voadeiras, há oito anos atrás. Ambas para trabalhar no transporte de turistas, uma eu mesmo pilotava e a outra eu contratava pilotos autônomos. Depois desisti e, apesar de ser mais lucrativo ter duas voadeiras, fiquei só com uma, pra eu mesmo pilotar, porque outros pilotos me davam mais dor de cabeça do que lucro. Mais ou menos em 1995 começou o interesse dos turistas pelos botos, antes não tinha, vinham só pra pescar e pra ir pra Vila do Marujá. Então, muitos barqueiros investiram em voadeiras, mas tínhamos problemas, como de cada um fazer seu preço e a competição pelo pequeno trapiche, o que causava muitos desentendimentos. Há cerca de três anos, todos os proprietários e pilotos de voadeiras e lanchas foram convidados a se unirem, porém somente 12 concordaram e batalharam para formar a "Associação Náutica Cananéia”, da qual hoje eu sou o tesoureiro. A Associação já trouxe benefícios de estrutura, por exemplo, uma barraca foi comprada e um pequeno deck construído para que os barqueiros fiquem à beira mar, à disposição dos turistas. Os valores dos passeios foram tabelados e hoje fazemos sorteios diários para ordem de atracamento e recebimento de turistas. Mas, apesar do sorteio ser levado a sério, a freguesia de cada um é respeitada, podendo o barqueiro passar a frente dos demais caso o turista assim solicite. Acho que os barcos não perturbam os botos, inclusive acredito que hoje tem muitos mais botos na baía do que antigamente. Estou satisfeito com meu trabalho e pretendo continuar trabalhando com este tipo de turismo."

Nota-se pelos depoimentos que são três pessoas que lutaram bastante, têm pontos de vista bem diferenciados, mas com um denominador comum. O segundo e o terceiro entrevistados têm uma visão mais prática e aplicada, enxergando a atividade como forma de sustento e lucro, ao passo que a primeira pessoa, além disso, encara a atividade como uma forma de valorizar e conservar a região como um todo.

Pelos depoimentos também é possível notar que até a década de 1960, não havia o interesse turístico em conhecer as outras comunidades, ou seja, provavelmente os poucos turistas que chegavam à região permaneciam nos locais de mais fácil acesso (Cananéia -ilha e continente), não utilizando transporte via embarcação. Foi a partir da década seguinte que teve início o turismo náutico na região, sendo a princípio dedicado exclusivamente à atividade de pesca amadora/ esportiva. Com o passar dos anos, o número de turistas interessados em fazer o translado entre ilhas e de conhecer a natureza da região aumentou e vem aumentando 
consideravelmente. Somente na década de 1990 é que descobriu-se na região que o boto-cinza poderia ser um grande atrativo turístico. Hoje, as empresas de escunas e muitos proprietários e pilotos de voadeiras da Ilha de Cananéia vivem exclusivamente do turismo de observação deste cetáceo. Nos meses de verão, ainda, alguns pescadores abandonam as atividades de pesca e passam a participar do transporte de turistas com seus barcos de pesca de madeira.

O fato da cooperação entre as empresas de escunas ter aumentado ao longo dos anos de atividade e a criação da Associação Náutica ente os pilotos e proprietários de voadeiras, sugere que o bom relacionamento entre estes profissionais tende a crescer, o que confere o desejado "bom ambiente" à atividade de turismo de observação de cetáceos (cf. IFAW et al., 1995). A visão de que pequenas associações trazem maiores facilidades do que investimentos individuais, permitiu maior desenvolvimento da atividade e ainda, possibilitou que pessoas simples, sem muito estudo e dinheiro, hoje possam contar com um bem sucedido negócio próprio, uma realidade bem diferente dos grandes centros urbanos.

Se por um lado este novo impulso desenvolvimentista do turismo pode ser a solução dos problemas econômicos, por outro lado pode ser sua destruição sobre o ponto de vista ambiental (Coscarella et al., 2003). Cananéia e Ilha Comprida são dois dos 15 municípios paulistas considerados Estâncias Balneárias pelo Estado de Sao Paulo, por cumprirem determinados pré-requisitos definidos por Lei Estadual. Tal status garante a esses municípios uma verba maior por parte do Estado para a promoção do turismo regional. Também, os municípios adquirem o direito de agregarem junto a seus nomes o título de Estância Balneária, termo pelo qual passam a ser designados tanto pelo expediente municipal oficial quanto pelas referências estaduais (Governo do Estado e São Paulo, 1989). Além disso, o Programa de Pólos Turísticos, previsto no Plano Nacional de Turismo da EMBRATUR (1992 apud Becker, 1995) cita o litoral sul paulista como uma das áreas de ampliação da oferta de instalações náuticas, com o estímulo à implantação de marinas no litoral. Este pode ser um processo perigoso, sob o ponto de vista da conservação do boto-cinza, pois segundo Filla (2008), a aproximação exagerada de embarcações é danosa aos animais e segundo Rezende (2008), o som produzido pelos motores das mesmas causa interferências negativas na população, por emitirem freqüências de som na mesma faixa das emitidas por Sotalia guianensis.

Os entrevistados afirmam ter mais botos agora na região do que antigamente e isto pode estar relacionado a um ciclo natural de distribuição, visto que na década de 1980 havia muitos 
botos nesta região, tendo um decréscimo nos anos de 1990, voltando a aumentar por volta de 1998 (Emygdio Monteiro-Filho, obs. pes.).

Ainda, nota-se pelos depoimentos que o interesse dos próprios entrevistados pelos botos aumentou consideravelmente no final dos anos 1990, quando eles passaram a procurar pelos animais para mostrar aos turistas. Antes disto, talvez não 'perdiam tempo' prestando a atenção na quantidade de animais presentes na área.

Uma terceira possibilidade para explicar o aumento de botos-cinza na região de Cananéia talvez seja o abandono dos animais de outras áreas próximas e deslocamento para regiões menos perturbadas. Num estudo realizado na Baía de Guaratuba, litoral sul do Estado do Paraná, Filla (2004) detectou o abandono quase total da área pelos botos, o que foi uma surpresa, uma vez que a região apresenta características semelhantes às outras áreas ocupadas por esta espécie de cetáceo. Provavelmente este abandono foi causado pelo grande aumento de tráfego de embarcações nesta área, principalmente próximo à pequena barra de ligação com o oceano.

A partir do levantamento da estrutura para turismo náutico e dos depoimentos dos entrevistados, é possível considerar o turismo como uma importante fonte de renda para a comunidade da região de Cananéia. Contudo, o mais indicado é que haja esforço conjunto na região para o desenvolvimento de um 'turismo responsável', que se distingue do 'turismo de massa' pelos seguintes aspectos: usa recursos que pertencem e/ ou são geridos pelas comunidades de acolhimento; traduz-se em empresas de pequena dimensão; privilegia o contato direto entre as populações locais e os visitantes, enfatiza o entendimento mútuo e igualitário entre ambos; privilegia um desenvolvimento amigo do ambiente; caracteriza-se pela autenticidade e assenta-se nas potencialidades locais (Davidson, 1997).

O turismo de menos impacto deve ainda ser abordado de forma sistêmica: 1) conjunto da organização estrutural, que compreende as políticas públicas e privadas relacionadas ao funcionamento do turismo e a infra-estrutura geral; 2) conjunto das ações operacionais, que envolve a dinâmica de atuação das organizações, como a oferta, produção, distribuição, demanda e consumo e 3) conjunto das relações ambientais, que são as conseqüências ecológicas, sociais, culturais e econômicas do turismo. "O equilíbrio entre estes grupos possibilitará um turismo mais humano, atendendo as necessidades ambientais e das comunidades receptoras, dos turistas e dos empresários, nesta ordem" (Gomes et al., 2006). 


\section{Conclusões}

Na região de Cananéia as estruturas de alojamento encontradas variam de acordo com os diferentes turistas que freqüentam esta região: aqueles que se hospedam nas pousadas, hotéis e clubes náuticos locais; aqueles que acampam e aqueles que têm casa na região, ou se hospedam na casa de parentes e amigos.

Os turistas também podem ser separados de acordo com uso que fazem das embarcações, ou seja, divididos em pescadores esportivos, que vêm exclusivamente para a pesca e eventualmente trazem a família e que fazem uso das garagens náuticas tanto para alugar quanto para guardar suas próprias embarcações; aqueles que realizam passeios de escunas ou voadeiras das comunidades; aqueles que têm embarcações próprias e garagens náuticas particulares e aqueles que geralmente não fazem uso de nenhum tipo de embarcação, exceto pela balsa que liga as ilhas de Cananéia e Comprida.

O turismo náutico na região teve início na década de 1970, sendo a princípio dedicado exclusivamente à atividade de pesca amadora/ esportiva. Somente na década de 1990 é que o boto-cinza começou a ser visto como um grande atrativo turístico, sendo atualmente a observação deste cetáceo uma importante fonte de renda local.

A visão de que pequenas associações trazem maiores facilidades do que investimentos individuais, permitiu maior desenvolvimento da atividade de observação do boto-cinza e ainda, possibilitou que pessoas simples, sem muito estudo e dinheiro, hoje possam contar com um bem sucedido negócio próprio, uma realidade bem diferente dos grandes centros urbanos.

Os entrevistados afirmam ter mais botos agora na região do que antigamente e isto pode estar relacionado a um ciclo natural de distribuição dos animais; ou com o desinteresse por parte dos barqueiros, anterior a 1990; ou ainda resultado de um abandono de outras áreas saturadas e o deslocamento de botos-cinza para a região de Cananéia.

O turismo náutico é uma importante fonte de renda para Cananéia, especialmente aquele relacionado à observação dos botos-cinza na natureza. Contudo, cuidados devem ser tomados na presença dos animais e uma atividade constante de conscientização deve ser realizada com pessoas da comunidade e turistas, visando a otimização da atividade turística e a conservação do boto-cinza e de seu habitat. 


\section{Referências}

ALBUQUERQUE, U. P. \& LUCENA, F. P. L. 2004. Métodos e técnicas na pesquisa etnobotânica. Olinda: Editora Livro Rápido - Grupo Elógica.

BARROS, W. B. 1991. Recent cetacean records for southeastern Brazil. Marine Mammal Science, 7(3): 296-306.

BECKER, B. K. 1995. Levantamento e avaliação da Política Federal de Turismo e seu impacto na região costeira. Brasília: Ministério do Meio Ambiente, MMA.

BERNARDI, J. V. E. 2001. Estudo quantitativo da estrutura florestal do Parque Estadual da Ilha do Cardoso - SP. Tese de Doutorado em Geociências e Meio Ambiente. Instituto de Geociências e Ciências Exatas. Universidade Estadual Paulista, Rio Claro.

BRANCO, A. 2005. Cultura caiçara: resgate de um povo. Peruíbe: Ed. Oficina do Livro e Cultura.

CARVALHO, C. T. 1963. Sobre um boto comum no litoral do Brasil. Revista Brasileira de Biologia, 23(3): 263-276.

COSCARELLA, M. A.; DANS, S. L.; CRESPO, E. A. \& PEDRAZA, S. N. 2003. Potential imapct of unregulated dolphin watching activities in Patagonia. J. Cetaceans Res. Manage 5(1): 77-84.

DAVIDSON, R. 1997. Tourism in Europe. Londres: Pitman Publishing.

DA SILVA, V. M. F.\& BEST, R. C. 1996. Sotalia fluviatilis. Mammalian Species N $N^{\circ}$ 27, p.1-7.

DAURA-JORGE, F. G. 2007. A dinâmica predador-presa e o comportamento do boto-cinza, Sotalia guianensis (Cetacea, Delphinidae), na Baía Norte de Santa Catarina, sul do Brasil. Dissertação de mestrado, Universidade Federal do Paraná, Curitiba.

DIEGUES, A. C. 2002. Povos e águas: inventário de áreas úmidas. $2^{\mathrm{a}}$ edição. São Paulo: Núcleo de apoio à Pesquisa sobre Populações Humanas e áreas Úmidas Brasileiras, NUPAUB - USP.

FILLA, G. F. 2004. Estimativa da densidade populacional e estrutura de agrupamento do boto-cinza Sotalia guianensis (Cetacea: Delphinidae) na baía de Guaratuba e na porção norte do Complexo Estuarino da Baía de Paranaguá, PR. Dissertação de Mestrado em Zoologia - Universidade Federal do Paraná, Curitiba. 67p.

FILLA, G. F. 2008. Monitoramento das interações entre o boto-cinza Sotalia guianensis e atividades de turismo no Complexo Estuarino-Lagunar de Cananéia, litoral sul do Estado de São Paulo. Tese de doutorado, Universidade Federal do Paraná.

FILLA, G. F. \& MONTEIRO-FILHO, E. L. A. Group structure of Sotalia guianensis in the bays within the coast of Paraná, south of Brazil. Journal of the Marine Biological Association of the United Kingdom, no prelo.

GOMES, B. M. A.; ROMANIELLO, M. M. \& SILVA, M. A. C. 2006. Os efeitos do turismo em comunidades receptoras: um estudo com moradores de Carrancas, MG, Brasil. PASOS. Revista de Turismo y Patrimônio Cultural, 43(3): 391-408.

GOVERNO DO ESTADO DE SÃO PAULO, 1989. Constituição Estadual, Artigo 146, $1^{\circ} \S$ e $2^{\circ} \S$, de 05 de outubro de 1989 (última atualização em 2007).

HAGUETTE, T. M. 1992. Metodologias qualitativas na sociologia. Rio de Janeiro: Ed. Vozes.

HENRIQUE, W. \& MENDES, I. A. 2001. Zoneamento ambiental em áreas costeiras: uma abordagem geomorfológica. In: GERARDI, L. H. O. \& MENDES, I. A., (org.). Teoria, técnica, espaços e atividades Temas de geografia contemporânea. Pgs. 199-222. Rio Claro: UNESP/ AGETEO, 432p.

IBGE (Instituto Brasileiro de Geografia e Estatística), 2007. Disponível em <www.ibge.gov.br> consulta em 27 de abril de 2007. 
IFAW (International Fund for Animal Welfare); TETHYS RESEARCH INSTITUTE \& EUROPE CONSERVATION. 1995. Report of the workshop on the Scientific Aspects of Managing Whale Watching. Montecastello di Vibio. Itália.

LEATHERWOOD, S. \& REEVES, R. R. 1983. The Sierra Club Handbook of Whales and Dolphins. São Francisco: Copyright, 302p.

MINISTÉRIO DO TURISMO. 2009. Disponível em <www.turismo.gov.br>consulta em 16/04/2009.

MONTEIRO-FILHO, E. L. A. 2000. Group organization of the dolphin Sotalia fluviatilis guianensis in an estuary of southeastern Brazil. Ciência e Cultura 52(2): 97-101.

NUNES, M. 2003. Do passado ao futuro dos moradores tradicionais da Estação Ecológica da Juréia - Itatins, SP. Dissertação de Mestrado. Depto de Geografia, Universidade de São Paulo, São Paulo, SP.

OLIVEIRA, M. R. 2003. Ecologia alimentar de Sotalia guianensis $e$ Pontoporia blainvillei (Cetacea, Delphinidae e Pontoporiidae) no litoral sul do Estado de São Paulo e litoral do Estado do Paraná. Dissertação de Mestrado, Universidade Federal do Paraná, Curitiba, PR. 79p.

OLIVEIRA, M.R.; ROSAS F. C. W.; PINHEIRO P. C.; SANTOS R.A. 2008. Alimentação. Págs. 91101. In: Monteiro-Filho ELA, Monteiro KDA (Org.) Biologia, ecologia e conservação do boto-cinza. São Paulo: Páginas \& Letras Editora e Gráfica LTDA.

PREFEITURA MUNICIPAL DE ILHA COMPRIDA, 2007. Disponível em $<$ www.ilhacomprida.sp.gov.br> consulta em 27/04/2007.

REZENDE, F. 2008. Alterações acústico comportamentais. Págs. 165-176. In: MONTEIRO-FILHO, E. L. A. \& MONTEIRO, K. D. A. (Org.). Biologia, ecologia e conservação do boto-cinza. São Paulo: Páginas \& Letras Editora e Gráfica LTDA.

RICHARDSON, R. J.; PERES, J. A. S.; WANDERLEY, J. C. V.; CORREIA, L. M.; \& PERES, M. H. M. 1999. Pesquisa social: métodos e técnicas. São Paulo: Ed. Atlas.

RODRIGUES, C. L. 2005. A Cultura Caiçara e Turismo no Bairro do Marujá, Ilha do Cardoso. In: Enciclopédia Caiçara, v.4: História e Memória Caiçara. Organizador Carlos Diegues. São Paulo: Editora HUCITEC - NUPAUB-CEC/USP.

ROSAS, F. C. W. 2000. Interações com a pesca, mortalidade, idade, reprodução e crescimento de Sotalia guianensis e Pontoporia blainvillei (Cetacea, Delphinidae e Pontoporiidae) no litoral sul do Estado de São Paulo e litoral do Estado do Paraná, Brasil. Tese de Doutorado em Zoologia. Universidade Federal do Paraná, Curitiba, PR. 145p.

SCHAEFFER-NOVELLI, Y.; MESQUITA, H. S. L. \& CINTRÒN-MOLERO, G. 1990. The Cananéia Lagoon Estuarine System, São Paulo, Brazil. Estuaries 13(2): 193-203.

SEMA/SP - Secretaria de Estado do Meio Ambiente/ SP. 1998. Em busca da Sustentabilidade: subsídios para discussão do plano de ação governamental pra o desenvolvimento sustentável. São Paulo: IBAMA, SMA, UNICAMP.

SIMÕES-LOPES, P. C. 1988. Sobre a ampliação da distribuição do gênero Sotalia Gray, 1866 (Cetacea, Delphinidae), para as águas do Estado de Santa Catarina, Brasil. Biotemas 1(1):58-62.

SNUC - Sistema Nacional de Unidades de Conservação. 2000. Lei $N^{o} 9.985$, de julho de 2000.

VIETLER, R. B. 2002. Métodos antropológicos como ferramentas para estudos em Etnobiologia e Etnoecologia. In: AMOROZO, M. C. DE M.; MING, L. C. \& SILVA, S. P. DA S. (Orgs). Métodos de coleta e análise de dados em Etonobiologia, Etnoecologia e disciplinas correlatas. p. 11-29. Rio Claro: UNESP-Rio Claro.

\section{Recebido em: 18/09/2008 (1 ${ }^{\text {a }}$ versão) $08 / 05 / 2009$ ( $2^{a}$ versão)}

